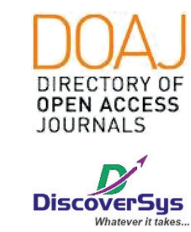

Published by DiscoverSys

\section{Karakteristik anemia pada lansia di RSUP Sanglah Denpasar pada bulan Januari-Juni 2017}

\author{
Alvi Laili Zahra, ${ }^{1 *}$ IB Putrawan, ${ }^{2}$ Tjokorda Gde Dharmayuda ${ }^{2}$
}

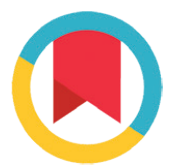

CrossMark

\title{
ABSTRACT
}

Background: Anemia is a symptom depending on the decrease of hemoglobin levels, the number of erythrocytes, and the volume of erythrocytes. The symptoms of anemia commonly occur in the elderly. In general, the common causes that often complained in the elderly are less efficient in absorbing some of the nutrients, decreased appetite due to illness, difficulty swallowing due to reducing of saliva, slow feeding, reduced teeth, and nausea. Anemia in the elderly should not be considered as an unavoidable consequence of aging. Treatment of this problem should start as early as possible.

Aim: This study aims to determine the characteristics of anemia in the elderly in RSUP Sanglah from January to June 2017.
Method: This research is a descriptive cross sectional study conducted at RSUP Sanglah Denpasar. Data obtained in the form of secondary data patient record period January - June 2017. Data were analyzed using Microsoft Excel 2010.

Result: Of the 102 patients, the average age was $69.3 \pm 7.1$ years with the highest proportion of patients aged $60-70$ years old is 56 people (54.9\%). The proportion of male is 71 people $(69,6 \%)$. of the total samples, there were 75 patients anemia patients $(73.5 \%)$ and 27 patients without anemia (26.5\%). The highest proportion of anemia depend on their stages are 51 patients of mild anemia (68\%). 47 patients (62.7\%) were normochromic and normocitary anemia. The highest proportion is anemia with kidney disease (38,7\%).

Keywords: elderly, geriatric problems, anemia

Cite This Article: Zahra, A.L., Putrawan, I.B., Dharmayuda, T.G. 2019. Karakteristik anemia pada lansia di RSUP Sanglah Denpasar pada bulan Januari-Juni 2017. Intisari Sains Medis 10(2): 155-158. D0I: 10.15562/ism.v10i2.241

\section{ABSTRAK}

Anemia merupakan suatu gejala yang ditandai oleh penurunan kadar hemoglobin, jumlah eritrosit dan volume eritrosit persatuan milimeter darah. Anemia merupakan salah satu gejala yang biasa terjadi pada lansia. Pada umumnya penyebab yang sering terjadi yaitu lansia kurang efisien dalam menyerap beberapa nutrisi yang dibutuhkan, menurunnya nafsu makan karena penyakit yang dideritanya, kesulitan menelan karena berkurangnya air liur, cara makan yang lambat, gigi yang berkurang dan mual. Anemia pada lansia sebaiknya tidak dianggap sebagai konsekuensi penuaan yang tidak dapat dihindari. Penanganan masalah ini seyogyanya sudah dimulai sedini mungkin.

Tujuan: Untuk mengetahui karakteristik anemia pada lansia di RSUP Sanglah Denpasar periode Januari-Juni 2017.
Metode: Penelitian ini merupakan penelitian deskritif cross sectional yang dilakukan di Rumah Sakit Umum Pusat (RSUP) Sanglah Denpasar. Data yang diperoleh berupa data sekunder rekam medis pasien periode Januari - Juni 2017. Data dianalisis dengan menggunakan program Microsoft Excel 2010.

Hasil: Dari 102 pasien, rata-rata berusia $69.3 \pm 7$.I tahun dengan proporsi terbanyak yaitu pasien berusia 60-70 tahun sejumah 56 orang (54,9\%). Jenis kelamin terbanyak yaitu laki-laki sejumlah 71 orang $(69,6 \%)$. Dari seluruh sampel terdapat pasien anemia sejumlah 75 pasien $(73,5 \%)$ dan tidak anemia sejumlah 27 pasien (26,5\%). Derajat anemia terbanyak yaitu anemia ringan berjumlah 51 pasien (68\%). 47 pasien (62,7\%) merupakan anemia normokromik normositer. Penyakit terbanyak pada lansia dengan anemia yaitu penyakit ginjal sejumlah 29 pasien (38,7\%).
'Program Studi Pendidikan Dokter Fakultas Kedokteran Universitas Udayana

${ }^{2}$ Bagian/SMF IImu Penyakit Dalam Fakultas Kedokteran Universitas Udayana/RSUP Sanglah, Denpasar

*Corresponding to: Alvi Laili Zahra, Program Studi Pendidikan Dokter Fakultas Kedokteran Universitas Udayana alvilailiz@gmail.com

Diterima: 09-04-2018

Disetujui: 15-07-2018

Diterbitkan: 01-08-2019
Kata kunci: anemia, lansia, problem geriatri

Cite Pasal Ini: Zahra, A.L., Putrawan, I.B., Dharmayuda, T.G. 2019. Karakteristik anemia pada lansia di RSUP Sanglah Denpasar pada bulan Januari-Juni 2017. Intisari Sains Medis 10(1): 155-158. D0I: 10.15562/ism.v10i2.241

\section{PENDAHULUAN}

Populasi lansia di Indonesia terus mengalami peningkatan. Data pada tahun 2015 menunjukkan terjadi peningkatan dari 7,6 persen menjadi 8,3 persen dari seluruh penduduk Indonesia setara dengan 20,24 juta jiwa. ${ }^{1}$ Peningkatan populasi lansia merupakan sebuah tantangan untuk pelayanan kesehatan Indonesia karena akan menimbulkan suatu permasalahan baru. Permasalahan tersebut meliputi penyakit degeneratif dan masalah gizi pada lansia yang terus meningkat. ${ }^{2} \mathrm{Hal}$ ini 
disebabkan karena lansia mengalami penurunan aktivitas fisik dan perubahan pola makan. ${ }^{3}$ Pada umumnya penyebab yang sering terjadi yaitu lanjut usia kurang efisien dalam menyerap beberapa nutrisi yang dibutuhkan, menurunnya nafsu makan karena penyakit yang dideritanya, kesulitan menelan karena berkurangnya air liur, cara makan yang lambat karena penyakit pada gigi, gigi yang berkurang dan mual. Faktor-faktor tersebut dapat memudahkan populasi lansia untuk terkena masalah gizi, salah satunya adalah anemia.

Pada tahun 2013, prevalensi anemia pada lansia mencapai 34,2\%. ${ }^{4}$ Pada lansia penurunan konsentrasi hemoglobin di bawah batas normal merupakan hal yang sering dijumpai dan dapat mengakibatkan permasalahan yang serius. ${ }^{5}$ Beberapa penelitian menyatakan anemia pada lansia dapat meningkatkan risiko penurunan kekuatan fisik, penurunan kekuatan otot, meningkatnya keletihan, kelemahan, frekuensi jatuh, meningkatkan risiko untuk dirawat di rumah sakit, menaikkan angka mortalitas dan keterbatasan fungsional serta gangguan kognitif pada lansia. ${ }^{5,6}$ Prevalensi gangguan fungsi kognitif termasuk demensia meningkat lebih dari $25 \%$ terjadi pada kelompok usia 85 tahun ke atas. ${ }^{6}$ Idealnya, fungsi kognitif yang baik sangat diperlukan agar seseorang dapat meningkatkan kualitas hidup terutama optimalisasi status fungsional, memulihkan produktifititas, kreatifitas dan perasaan bahagianya. Oleh karena itu, penurunan fungsi kognitif sebelum waktunya merupakan masalah serius. ${ }^{7}$

Anemia pada lansia sebaiknya tidak dianggap sebagai konsekuensi penuaan yang tidak dapat dihindari. Penanganan masalah ini seyogyanya sudah dimulai sedini mungkin. Penanganan tersebut berupa pencegahan atau upaya mempertahankan fungsi kognitif dikalangan usia lanjut, baik dengan upaya sosial ataupun dengan cara pencegahan penyakit. ${ }^{8}$ Untuk mengetahui mutu pelayanan kesehatan yang diselenggarakan perlu adanya data karakteristik anemia. Oleh karena itu, untuk menunjang pendekatan serta penanganan, penting untuk mengetahui karakteristik anemia pada lansia di RSUP Sanglah Denpasar, Bali.

\section{METODE}

Penelitian ini merupakan penelitian deskritif dengan desain rancangan cross-sectional dan pendekatan retrospektif yang dilakukan di Rumah Sakit Umum Pusat (RSUP) Sanglah Denpasar. Kriteria inklusi yang digunakan yaitu seluruh pasien dengan batasan usia di atas 60 tahun yang memeriksakan diri di Poliklinik Penyakit Dalam RSUP Sanglah Denpasar periode 1 Januari hingga 31 Juni 2017. Kriteria eksklusi yang digunakan yaitu data pasien yang tidak tersedia atau tidak lengkap meliputi jenis kelamin, usia, keluhan utama datang ke rumah sakit dan hasil laboratorium darah lengkap.

Data yang diperoleh berupa data sekunder rekam medis pasien periode 1 Januari hingga 31 Juni 2017. Data yang dicari meliputi biodata pasien, keluhan utama dan hasil laboratorium darah lengkap yaitu kadar hemoglobin, MCV, MCH, MCHC. Data yang memenuhi kriteria inklusi akan diambil sebagai sampel penelitian. Data yang terkumpul akan dianalisis secara deskriptif dengan Microsoft Excel 2010. Data yang telah dianalisis selanjutnya disajikan dalam bentuk tabel.

\section{HASIL}

Hasil penelitian dalam periode Januari hingga Juni 2017 terdapat 102 data rekam medis yang dapat diteliti. Pasien yang dominan yaitu laki-laki sejumlah 71 pasien $(69,6 \%)$ dibandingkan dengan perempuan 31 pasien $(30,4 \%)$. Rerata usia sampel yaitu 69,3 tahun. Rerata kadar Hb, MCV, MCH dan MCHC sampel yaitu 9,8 gr/dL, 88,3 fL, 28,0 pg, $30,86 \%$. Sejumlah 41 pasien $(40,1 \%)$ merupakan pasien penyakit ginjal.

Pada Tabel 2 memperlihatkan distribusi anemia berdasarkan kadar hemoglobin. Hasil penelitian menunjukkan bahwa lanjut usia di RSUP Sanglah berdasarkan hasil laboratorium ada yang anemia dan tidak anemia. Diagram di atas menunjukkan

\section{Tabel 1 Karakteristik sampel}

\begin{tabular}{lcc}
\hline Karakteristik & Jumlah & $\%$ \\
\hline Jenis Kelamin & 71 & 69,6 \\
$\quad$ Laki-laki & 31 & 30,4 \\
$\quad$ Perempuan & $69.3 \pm 7 . I$ \\
Umur (Mean \pm SD) & 56 & 54,9 \\
$\quad 60-70$ tahun & 37 & 36,3 \\
$70-80$ tahun & 8 & 7,84 \\
$80-90$ tahun & 1 & 0,98 \\
$>90$ tahun & $9.8 \pm 2.79$ \\
Hb (Mean \pm SD) & $88.3 \pm 12.28$ \\
MCV (Mean \pm SD) & $28.0 \pm 5.92$ \\
MCH (Mean \pm SD) & $30.86 \pm 2.25$ \\
MCHC (Mean \pm SD) & \multicolumn{2}{c}{4,9} \\
Penyakit & 5 & 40,1 \\
Defisiensi besi & 41 & 36,3 \\
Penyakit ginjal & 37 & 13,7 \\
Penyakit kronik dan inflamasi & 14 & 4,9 \\
Keganasan hematologi & 5 & \\
Lain-lain & &
\end{tabular}

* Rerata \pm Simpang Baku 
Tabel 2 Distribusi anemia berdasarkan kadar hemoglobin

\begin{tabular}{lc}
\hline Status Anemia & Jumlah (\%) \\
\hline Anemia & $75(73,5)$ \\
Tidak anemia & $27(26,5)$ \\
\hline
\end{tabular}

Tabel 3 Distribusi anemia berdasarkan umur

\begin{tabular}{lcc}
\hline Umur & Anemia $(\mathbf{N}=\mathbf{7 5})$ & Non Anemia $(\mathbf{N}=\mathbf{2 7})$ \\
\hline $60-70$ tahun & 39 & 17 \\
$70-80$ tahun & 27 & 10 \\
$80-90$ tahun & 7 & 1 \\
$>90$ tahun & 1 & 0 \\
\hline
\end{tabular}

Tabel 4 Frekuensi jenis kelamin pada kelompok anemia

\begin{tabular}{lcc}
\hline Jenis Kelamin & Anemia (N=75) & Persen (\%) \\
\hline Laki - laki & 50 & 66,6 \\
Perempuan & 25 & 33,3 \\
\hline
\end{tabular}

Tabel 5 Distribusi anemia berdasarkan derajat anemia

\begin{tabular}{lcc}
\hline Derajat Anemia & Jumlah $(\mathbf{N}=\mathbf{7 5})$ & Persen (\%) \\
\hline Ringan & 51 & 68,0 \\
Sedang & 19 & 25.3 \\
Berat & 5 & 6,70 \\
\hline
\end{tabular}

Tabel 6 Distribusi anemia berdasarkan morfologi eritrosit

\begin{tabular}{lcc}
\hline Morfologi Eritrosit & Jumlah (N=55) & Persen (\%) \\
\hline Normokromik Normositer & 47 & 62,7 \\
Hipokromik Mikrositer & 16 & 21,3 \\
Makrositer & 12 & 16,0 \\
\hline
\end{tabular}

Tabel 7 Distribusi anemia berdasarkan etiopatogenesis

\begin{tabular}{lcc}
\hline Etiopatogenesis & Jumlah (N=55) & $\begin{array}{c}\text { Persen } \\
\text { (\%) }\end{array}$ \\
\hline Defisiensi besi & 5 & $6,7 \%$ \\
Penyakit Ginjal & 29 & $38.7 \%$ \\
Penyakit kronis atau inflamasi & 26 & $34.7 \%$ \\
Keganasan pada hematologi & 11 & $14,7 \%$ \\
Lain-lain & 4 & $5,3 \%$ \\
\hline
\end{tabular}

bahwa status anemia pada pasien lanjut usia yang anemia sebanyak 75 pasien atau $73,5 \%$, sedangkan yang tidak anemia sebanyak 27 pasien yaitu $26,5 \%$.

Pada Tabel 3 memperlihatkan bahwa distribusi anemia berdasarkan umur tertinggi yaitu pasien yang berumur lebih dari 90 tahun sebanyak 1 pasien dengan presentase $100 \%$ dan terendah pada pasien umur 60-70 tahun sebanyak 39 pasien dengan presentase $69,6 \%$.
Laki-laki dominan terkena anemia dari pada perempuan. Pada Tabel 4, Sejumlah 66,6\% dari pasien merupakan laki-laki.

Pada Tabel 5 memperlihatkan bahwa distribusi diatas diketahui derajat anemia paling banyak terdapat pada tingkat anemia ringan yaitu 51 pasien atau $68,0 \%$ dan anemia sedang sebanyak 19 pasien atau $25,3 \%$. Jumlah pasien anemia berat adalah 5 pasien $(6,7 \%)$.

Pada Tabel 6 memperlihatkan bahwa distribusi anemia berdasarkan morfologi eritrosit paling banyak adalah anemia normokromik normositer sebanyak 47 pasien (62,7\%).

Distribusi anemia berdasarkan etiopatogenesis dapat dilihat pada Tabel 7. Distribusi terbanyak disebabkan karena penyakit ginjal yaitu 38,7\%.

\section{PEMBAHASAN}

Penelitian ini menunjukkan bahwa presentase kelompok usia diatas 90 tahun mengalami anemia cenderung lebih besar dibanding dengan kelompok usia yang lain. Penelitian serupa didapat pada penelitian yang dilakukan oleh Collins dkk pada tahun 2016 pada populasi US dari tahun 2003 hingga 2012 menunjukkan bahwa kelompok usia paling tinggi mengalami anemia adalah kelompok usia 80-85 tahun dengan presentase $19.4 \%$, sedangkan pada kelompok usia 70-79 tahun dan 60-69 tahun yaitu $12.4 \%$ dan $6.5 \%$ dari total populasi sampel. ${ }^{9}$ Perbedaan hasil didapat pada penelitian Mauro T dkk, tahun 2010 di Biella, Italy menunjukkan bahwa proporsi anemia pada lanjut usia lebih tinggi pada lanjut usia awal (65-84 tahun) dari pada lanjut usia II ( $<85$ tahhun)..$^{10}$ Giesel dalam penelitiannya pada tahun 2013 di Frankfurt, Germany mengatakan mengatakan bahwa antara umur dan kadar hemoglobin tidak ditemukan adanya korelasi. ${ }^{11}$ Perbedaan yang terjadi dapat dikarenakan kadar hemoglobin seseorang dipengaruhi oleh pola makan dan penyakit yang menyertai. ${ }^{12}$

Selain umur terdapat faktor risiko lain yang mempengaruhi terjadinya anemia yaitu jenis kelamin. Hasil penelitian ini menunjukkan proporsi berdasarkan jenis kelamin pada kelompok anemia yaitu $66,6 \%$ dan 33,3\% untuk laki-laki dan perempuan. Pendapat serupa ditemukan pada penelitian Prasetya dkk pada Panti Sosial Tresna Werdha Abiyoso di Yogyakarta pada tahun 2013 mengatakan bahwa kejadian anemia pada lanjut usia yaitu $72.22 \%$ laki-laki dan $23.08 \%$ perempuan. ${ }^{13}$ Penelitian Tettamanti dkk, tahun 2010 di Biella, Italy mengatakan bahwa proporsi anemia pada lakilaki (52.8\%) lebih besar dari perempuan (47.1\%). ${ }^{10}$ Perbedaan pendapat terletak pada penelitian Collins dkk pada tahun 2016 pada populasi US dari tahun 2003 hingga 2012 yaitu dengan perbandingan 
laki-laki dan perempuan 3,5 dan 7,6. ${ }^{9}$ Hasil penelitian yang berbeda tentang jenis kelamin dipengaruhi oleh beberapa faktor seperti gaya hidup, pola makan, kebiasaan merokok, dan jumlah subjek laki-laki lebih banyak daripada jumlah subjek perempuan. Selain itu, kepedulian perempuan terhadap kesehatannya juga lebih tinggi dibandingkan dengan laki-laki. Hal itu dapat juga mempengaruhi hasil yang akan didapat pada berbagai penelitian. ${ }^{14}$

Distribusi anemia berdasarkan derajat anemia pada RSUP sanglah yaitu anemia ringan 68\%, sedang $25,3 \%$ dan berat $6,7 \%$. Penelitian serupa yang dilakukan oleh Prasetya dkk menunjukkan anemia ringan $72,97 \%$, sedang $27.03 \%$ dan berat 0\%. ${ }^{13}$ Penelitian Tettamanti pada tahun 2010 menunjukkan bahwa anemia ringan $83 \%$, sedang $13.5 \%$ dan anemia berat $0.3 \%{ }^{10}$ Penelitian lain menunjukkan hasil yang serupa yaitu anemia ringan (85.1\%), sedang (13.5\%) dan berat $(1,5 \%){ }^{11}$ Dari beberapa penelitian yang telah dilakukan tidak ada perbedaan pada hasil penelitian.

Anemia dapat diklasifikasikan dengan berbagai cara tergantung dari sudut mana kita melihat dan melakukan klasifikasi. Salah satu klasifikasinya yaitu berdasarkan morfologi eritrositnya pada pemeriksaan apusan darah atau dengan melihat indeks eritrosit. Penelitian ini mendapatkan hasil bahwa gambaran morfologi darah anemia lanjut usia memiliki klasifikasi normokromik normositer $62,7 \% \%$, hipokromik mikrositer $21,3 \%$ dan makrositer 16\%. Penelitian Prasetya dkk menjelaskan bahwa gambaran morfologi darah anemia lanjut usia memiliki klasifikasi anemia hipokromik mikrositik sebesar $12.5 \%$ dan anemia normokromik-normositer sebanyak 87.5\%. ${ }^{13}$ Penelitian Prakash dkk tahun 2015 di Karnataka, India mengatakan bahwa gambaran morfologi eritrosit pada pasien Rumah Sakit Victoria memiliki klasifikasi 52\% normokromik normositer, 32\% mikrositik mikrositer dan 16\% makrositer. ${ }^{15}$ Hasil tersebut menunjukkan bahwa kasus anemia terbanyak yang ditemukan adalah anemia normokromik normositer.

Anemia juga dapat diklasifikasi menurut etiopatogenesisnya, yang paling banyak mengakibatkan anemia pada lansia adalah penyakit ginjal (38,7\%), penyakit kronik atau inflamasi $(34,7 \%)$ dan keganasan pada hematologi $(14,7 \%)$. Pada penelitian Prakash dkk menyebutkan bahwa masalah banyak ditemukan pada anemia pada lansia di Rumah Sakit Victoria adalah penyakit kronik dan inflamasi (26\%), defisiensi besi (24\%) dan keganasan pada hematologi (18\%). ${ }^{14}$ Pada penelitian Geisel dkk menunjukkan bahwa penyakit yang sering menyebabkan anemia adalah defisien besi (65\%) dan penyakit kronis dan inflamasi (21.4\%). ${ }^{11}$ Perbedaan tersebut dapat disebabkan karena perbedaan jumlah sample dan tempat dilakukannya penelitian.

\section{SIMPULAN}

Berdasarkan hasil penelitian yang dilakukan di RSUP Sanglah, diperoleh simpulan bahwa presentase anemia pada lansia kelompok usia diatas 90 tahun lebih besar dibandingkan dengan usia 60-70 tahun, 70-80 tahun dan 80-90 tahun. Proporsi anemia pada laki-laki lebih besar dari pada perempuan. Distribusi anemia berdasarkan derajatnya anemia ringan lebih banyak ditemukan dari pada anemia sedang dan berat. Gambaran morfologi darah anemia lanjut usia lebih banyak ditemukan normokromik normositer dibandingkan dengan hipokromik mikrositer maupun maksositer. Distribusi anemia berdasarkan etiopatogenesisnya tertinggi pada penyakit ginjal.

\section{DAFTAR PUSTAKA}

1. Badan Pusat Statistik. Statistik Penduduk Lanjut Usia; 2015.

2. Bianchi VE. Anemia in The Elderly Population. J Hematol. 2014;3(4):95-106

3. Olivers M, Hertrampf, Capurro, Wegner D. Prevalence of anemia in elderly subject living at home: role of micronutrient deficiency and inflammation. 2000; 834-839

4. Riskesdas. Badan Penelitian dan Pengembangan Kesehatan; 2013.

5. Lucca U dkk. Association of Mild Anemia with Cognitive, Functional, Mood and Quality of Life Outcomes in The Elderly. The Health and Anemia Study. 2008;3

6. Santos IS, Lotufo PA, Menezes PR, Bense IM. Anemia and Dementia Among The Elderly. The Sao Paulo Ageing and Health Study. 2012; 74-81

7. Belakang AL. Penurunan Fungsi Kognitif pada Lansia. Geriatric J. 2003;1(6):56

8. Wreksoatmodjo BR. Aktivitas Kognitif Mempengaruhi Fungsi Kognitif Lanjut Usia di Jakarta. 2015;42:7-13

9. Le CHH. The Prevalence of Anemia and Moderate-Severe Anemia in the US Population (NHANES 2003-2012). PloSONE 2016; 11(11).

10. Tettamanti M, Lucca U, Gandini F, Recchia A, Mosconi P, Apolone G, Nobili A, Tallone MV, Detoma P, Giacomin A, Clerico M, Tempia P, Savoia L, Fasolo G, Ponchio L, Della Porta MG, and Riva E. Prevalence, incidence and types of mild anemia in the elderly: the Health and Anemia population-based study. Haematologica 2010;95(11):1849-1856

11. Geisel T, Martin J, Schulze B, Schaefer R, Bash M, Virgin G, Stein J. An Etiologic Profile of Anemia in 405 Geriatric Patients. Hindawi Publishing Corporation. 2014;10.1155

12. Siregar RD, Arneliwati, Nauli FA. Hubungan Status Gizi Terhadap Kejadian Anemia pada Lansia. Universitas Riau; 2014

13. Prasetya HR, Sistiyono, Naur MEE. 2013. Gambaran Anemia pada Lanjut Usia di Panti Sosial Tresna Werdha Abiyoso Tahun 2013. Yogyakarta

14. Prakash KG, Devendrappa KR, Madhukumar $\mathrm{MH}$, Priyashree R, Avinash BH. Clinical Profile of Anemia in Elderly: A Cross Sectional Study from a Tertiary Care Centre.Scholars Journal of Applied Medical Sciences. 2015;3(3C):1266-1270

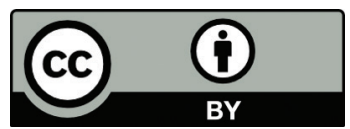

This work is licensed under a Creative Commons Attribution 